Article

\title{
Preparation and Characterization of Carbon Paste Electrode Bulk-Modified with Multiwalled Carbon Nanotubes and Its Application in a Sensitive Assay of Antihyperlipidemic Simvastatin in Biological Samples
}

\author{
Amir M. Ashrafi and Lukáš Richtera *D \\ Department of Microelectronics, Faculty of Electrical Engineering and Communication, Brno University of \\ Technology, Technická 3058/10, CZ-616 00 Brno, Czech Republic; amirmansoor.ashrafi@mendelu.cz \\ * Correspondence: richtera@mendelu.cz; Tel.: +420-545-133-311
}

Academic Editor: Ondrej Zitka

Received: 20 May 2019; Accepted: 12 June 2019; Published: 13 June 2019

\begin{abstract}
Determination of an antihyperlipidemic drug simvastatin (SIM) was carried out using a carbon paste electrode bulk-modified with multiwalled carbon nanotubes (MWCNT-CPE). Scanning electrochemical microscopy (SECM), scanning electron microscopy (SEM), and atomic force microscopy (AFM) were used for the characterization of the prepared electrodes. Different electrodes were prepared varying in mass percentage of MWCNTs to find out the optimum amount of MWCNTs in the paste. The MWCNT-CPE in which the mass percentage of MWCNTs was 25\% $(w / w)$ was found as the optimum. Then, the prepared electrode was used in a mechanistic study and sensitive assay of SIM in pharmaceutical dosage form and a spiked human plasma sample using differential pulse voltammetry (DPV). The prepared electrode shows better sensitivity compared to the bare carbon paste and glassy carbon electrode (GCE). The detection limit and the limit of quantification were calculated to be $2.4 \times 10^{-7}$ and $8 \times 10^{-7}$, respectively. The reproducibility of the electrode was confirmed by the low value of the relative standard deviation $(\mathrm{RSD} \%=4.8 \%)$ when eight measurements of the same sample were carried out. Determination of SIM in pharmaceutical dosage form was successfully performed with a bias of $0.3 \%$ and relative recovery rate of $99.7 \%$. Furthermore, the human plasma as a more complicated matrix was spiked with a known concentration of SIM and the spiking recovery rate was determined with the developed method to be $99.5 \%$.
\end{abstract}

Keywords: multiwalled carbon nanotube; carbon paste electrode; scanning electrochemical microscopy; simvastatin determination; mechanism study; biological sample

\section{Introduction}

Simvastatin (SIM) is a long-established hydroxy-methylglutaryl coenzyme which was first introduced in 1998 [1]. It belongs to a group of drugs called statins. The oral administration of SIM is followed by its hydrolysis, generating the corresponding $\beta$-hydroxyacid form [2]. Then, the content of the low-density lipoprotein (LDL) cholesterol in plasma is reduced effectively by inhibition of 3-hydroxy-3-methylglutaryl-coenzyme A (HMG-CoA) reductase [3]. This enzyme acts by catalyzing the conversion of HMG-CoA to mevalonate, which is an early and rate-limiting step in the biosynthesis of cholesterol [4]. SIM is synthesized from a fermentation product of Aspergillus terreus [5]. In addition to the well-defined function of statins, some clinical trials showed that this group of drugs can protect against cardiovascular disease (CVD) through another mechanism [6]. Statins are among the most widely prescribed drugs in the world [7]. 
Due to the in vivo hydrolysis, the concentration of SIM in human plasma is very low (1-15 nM) [8-11]. Moreover, for the determination of SIM in plasma, a separation step is required. Thus, it is highly demanded to develop a sensitive analytical method for the determination of SIM in pharmaceutical dosage form and human plasma. The developed analytical methods for the determination of SIM consist of methods which provide the separation process, including high-performance liquid chromatography (HPLC) [2,12-15], gas chromatography (GC) [16], and capillary electrophoresis [17] in combination with detection methods including ultraviolet (UV) spectroscopy [12], fluorescence detection [14], mass spectrometry $[2,13,15,16]$, and colorimetry [18].

However, the inherent features of electroanalytical methods, such as good selectivity and sensitivity, even in a complicated matrix, as well as being inexpensive, quick, and simple to execute, make them advantageous compared to the other analytical methods.

Several electroanalytical methods were applied for the determination of SIM, including adsorption of the SIM-Cd(II) complex at the mercury drop electrode and determination of SIM from the reduction peak of cadmium [19], cathodic square-wave stripping voltammetry using the adsorption of SIM onto the mercury electrode surface [20], direct voltammetry using the bare glassy carbon electrode (GCE) [21], GCE immobilized with sodium dodecyl sulfate [22], and GCE modified with a multiwalled carbon nanotube (MWCNT)-dihexadecyl hydrogen phosphate composite [23]. Although, these electroanalytical techniques showed good sensitivity, there are still some disadvantages, such as toxicity of the mercury and the short life of the surface-modified electrodes.

Blending the graphite powder with a pasting liquid forms a heterogeneous mixture which is known as carbon paste. Carbon paste is an attractive electrode material due to its electrochemical characteristics, including a very low background current, low ohmic resistance, cost-effectiveness, and simple electrode surface renewal [24]. Furthermore, the modification of the carbon paste can be simply carried out by adding the modifier to the paste [25-27]. To decrease the electrical resistance of the paste, room-temperature ionic liquids were used as a pasting liquid [28].

As a modifier, carbon nanotubes (CNTs) enhance the electrode performance by increasing the velocity of the electron transfer [29]. Moreover, reduced over-potential and improved selectivity are caused by modifying the electrode with CNTs [30]. In addition, CNTs possess a significant adsorption capability, which provides pre-concentration of the analyte at the electrode surface and consequently increases the sensitivity of the electrode. The sensitivity of the electrode is also improved due to the high surface area of CNTs [31].

This work aimed to prepare a carbon paste electrode (CPE) bulk-modified with MWCNTs for sensitive determination of SIM. Differential pulse voltammetry was used for the determination. The MWCNTs can increase the sensitivity of the concentration determination compared to the bare GCE and CPE. The preparation and surface renewing of the MWCNTs/CPE are rapid and easy. Moreover, compared to the previous studies, any toxic compounds such as mercury or other heavy metals are not used. Then, the developed electrode was used to determine SIM in human plasma and in the pharmaceutical dosage form.

\section{Results and Discussion}

\subsection{Scanning Electrochemical Microscopy (SECM) Analysis}

SECM images of three MWCNT-CPEs which differ in mass percentage of MWCNTs are shown in Figure 1. In SECM, a constant height and a homogeneous surface represent a slight current gradient, while the surfaces with lower homogeneity show a significant current gradient. The MWCNT-CPE with $25 \%$ MWCNTs shows a relatively homogeneous current which can be attributed to a higher degree of surface homogeneity. The current gradient shows some degrees of inhomogeneity in the cases of $15 \%$ and $35 \%$ MWCNTs, where some peaks or continuous changes in current profile can be observed. Recalling that the paste is a heterogeneous mixture of three components, it can be concluded that the MWCNT-CPE with $25 \%$ MWCNTs is optimal to achieve the highest homogeneity of the mixture. As a matter of experience, 
MWCNTs adsorb more oil compared to graphite. Hence, the 15\% MWCNT-CPE is more lubricated. On the other hand, the 35\% MWCNT-CPE paste is drier. Thus, the binding of the component is not efficient. The effect of the binder/graphite powder ratio on the carbon paste properties was investigated using different characterization methods. It was shown that, with a low amount of organic oil, the binding of the graphite powder is not well established, while a high amount of oil causes increased resistivity of the paste [32]. It is worth noting that each SECM analysis was repeated at least three times for each prepared electrode, and similar results were obtained.
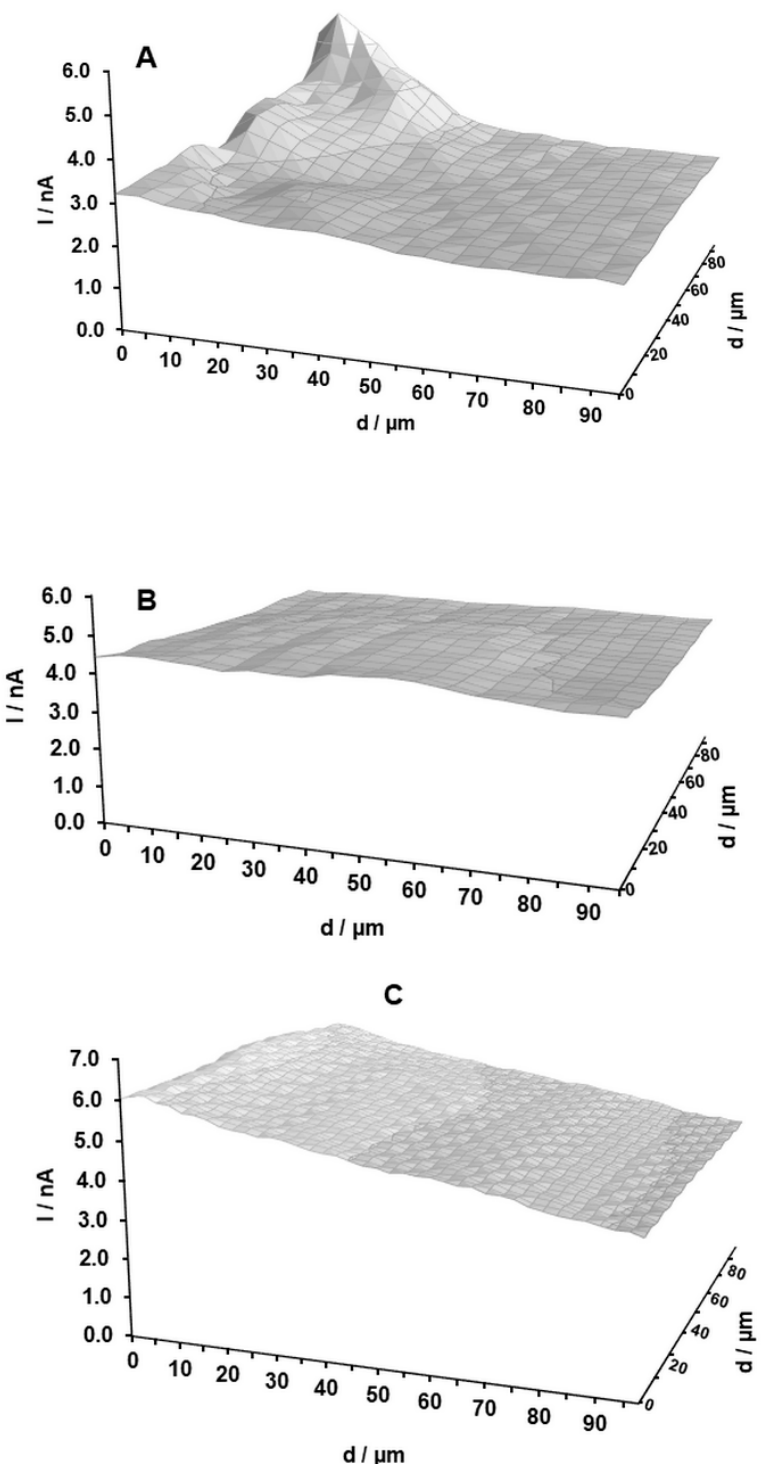

Figure 1. Scanning electrochemical microscopy (SECM) images of the multiwalled carbon nanotube carbon paste electrodes (MWCNT-CPEs): (A) 15\% MWCNT-CPE; (B) 25\% MWCNT-CPE; (C) 35\% MWCNT-CPE. Measurement conditions: Pt ultra-microelectrode (UME) with $10 \mu \mathrm{m}$ diameter and RG (the ratio of the insulator radius to the electrode radius) $\geq 10, \mathrm{FCOH} 0.2 \mathrm{mM}$, and $\mathrm{KCl} 0.1 \mathrm{M}$; $0.6 \mathrm{~V}$ was applied at the tip; the scan rate of the tip to the substrate was $0.5 \mu \mathrm{m} \cdot \mathrm{s}^{-1}$. The tip approached to the substrate until $i_{T}=1.25 i_{T, \infty}$.

\subsection{SEM Analysis}

The SEM images of the three kinds of prepared electrodes are presented in Figure 2. The inhomogeneity of the $15 \%$ and $35 \%$ MWCNT electrodes can be attributed to more defects, which are visible on the electrode surface. The defects are formed due to the ineffective binding of the paste components because of the 
unjustified mass ratio of the components. The surface of the $25 \%$ MWCNT electrode shows less defects, which indicates higher homogeneity of the electrode surface.

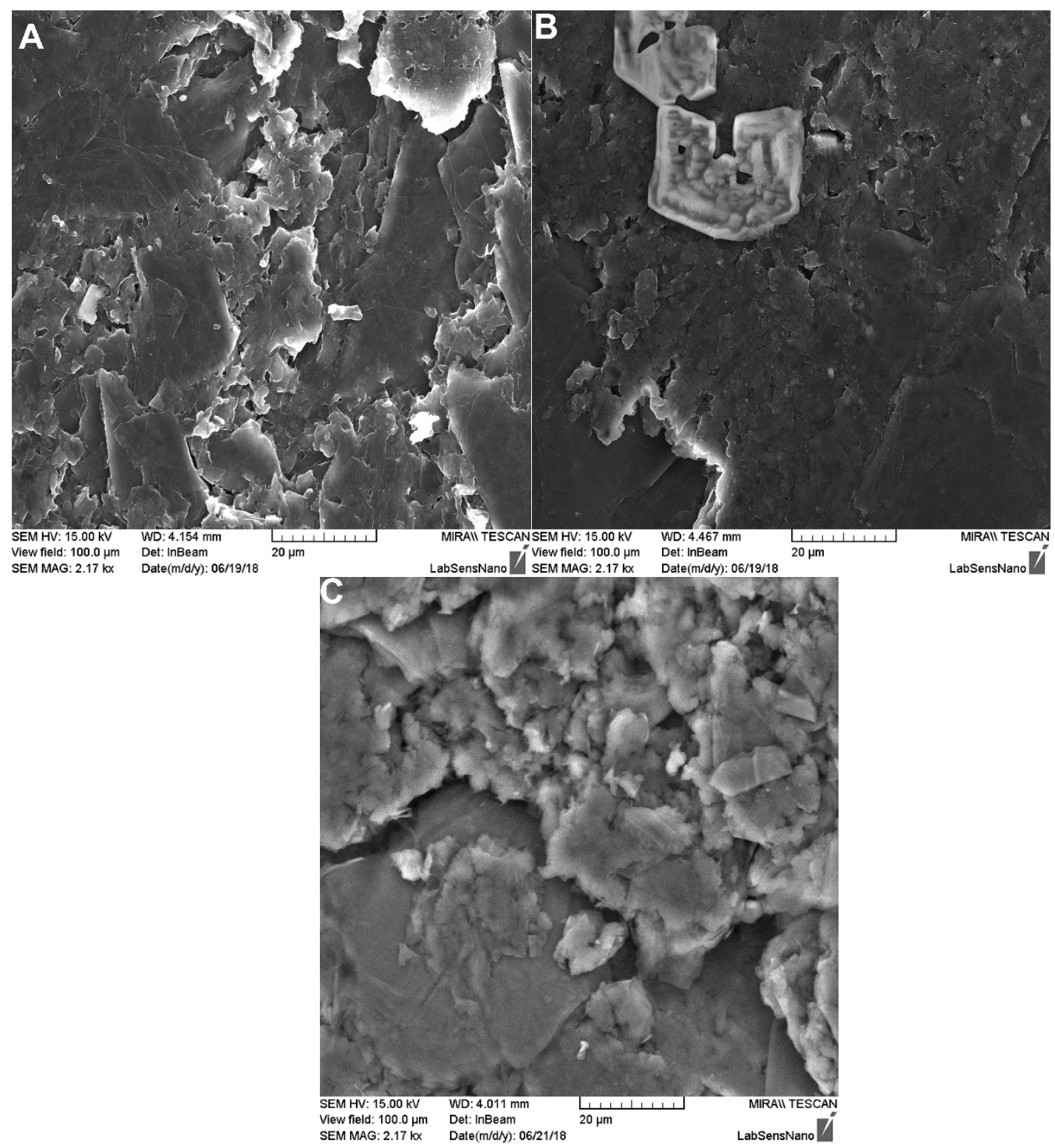

Figure 2. The SEM images of the prepared MWCNT-CPEs: (A) 15\% MWCNT-CPE; (B) 25\% MWCNT-CPE; (C) $35 \%$ MWCNT-CPE.

Based on the obtained results, the 25\% MWCNT-CPE was selected as the optimum electrode and used for the further experiments. It was used for the determination of SIM to get insight into its electroanalytical properties.

\subsection{Atomic Force Microscopy (AFM) Analysis}

The three-dimensional (3D) AFM images of the developed electrodes are shown in Figure 3. The two-dimensional (2D) AFM images are also available in Figure S1. The presence of the MWCNTs on each prepared electrode is apparent. As seen, the MWCNTs are randomly distributed over the electrode surface. The bright spots around the MWCNTs are probably attributed to the mineral oil. As seen in Figure S1, the 35\% MWCNT-CPE seems to be dry as the MWCNTs are not surrounded by the mineral oil. On the other hand, the MWCNTs in the 15\% and 25\% MWCNT-CPEs are well 
mixed with the mineral oil. The dryness of the electrode with 35\% MWCNTs stems from the higher capacity of the MWCNTs in the adsorption of the mineral oil. Hence, the higher mass percentage of the MWCNTs requires more mineral oil.

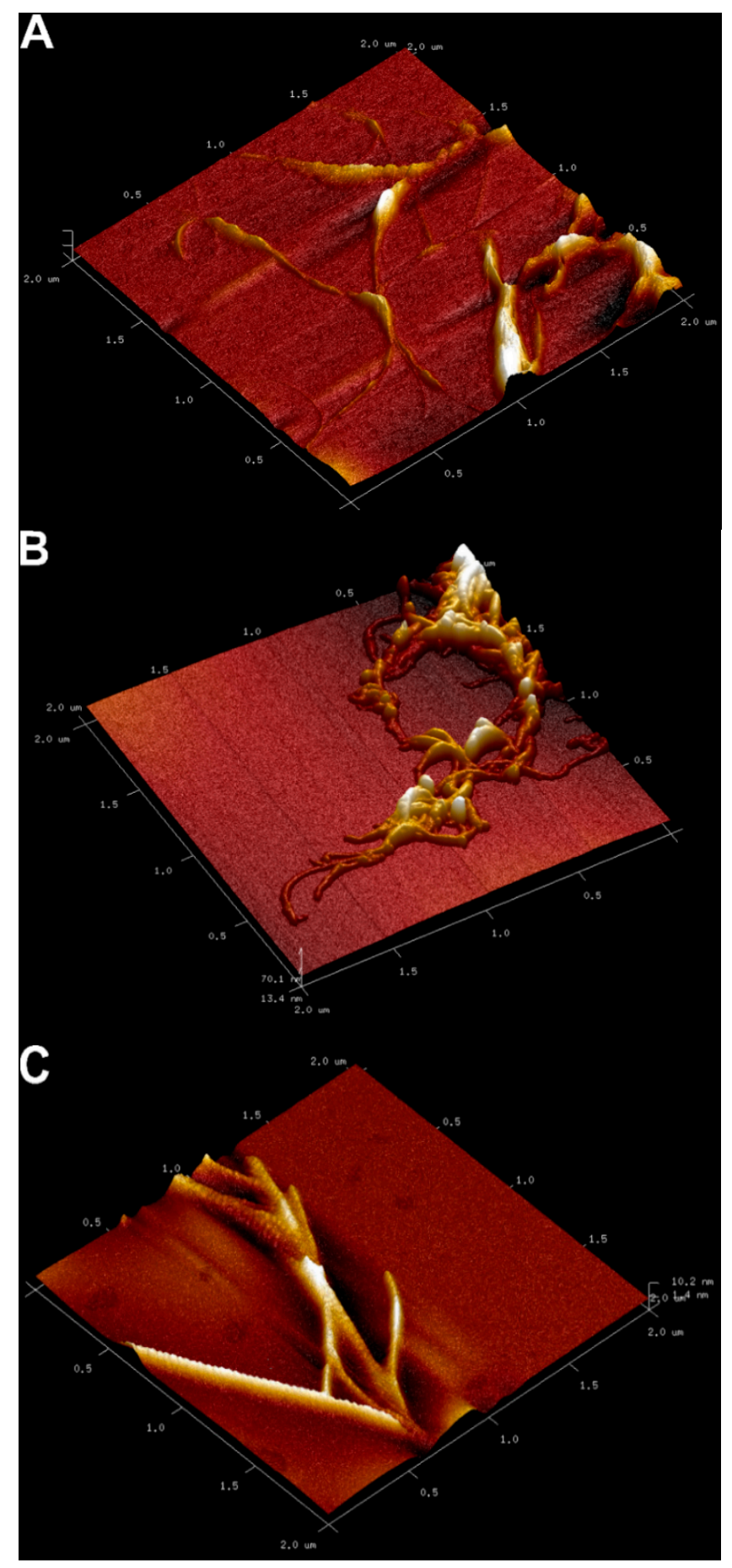

Figure 3. Atomic force microscopy (AFM) images of the prepared MW-CNTCPEs: (A) 15\% MWCNT-CPE; (B) 25\% MWCNT-CPE; (C) 35\% MWCNT-CPE.

\subsection{Electrochemical Behavior of SIM on the MWCNT-CPES}

The CV of SIM shows a distinctive irreversible oxidation taking place at $1.2 \mathrm{~V}$ in $0.1 \mathrm{M} \mathrm{H}_{2} \mathrm{SO}_{4} \mathrm{pH}$ (Figure 4). The probable oxidation mechanism is also shown in Figure 4. To get more insight into the nature of the oxidation of the SIM, the $\mathrm{pH}$ dependence of the peak current and potential was studied. 


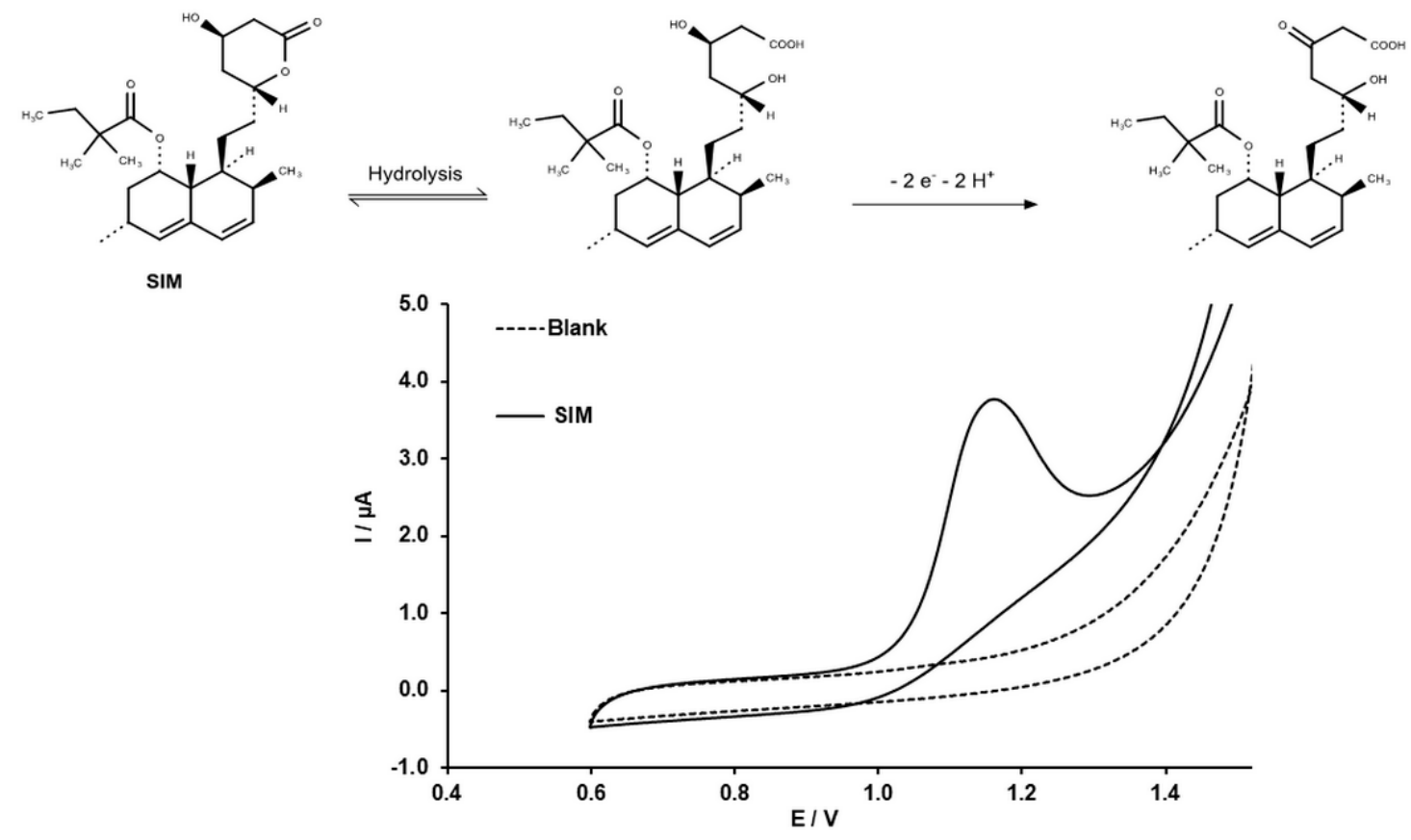

Figure 4. The CV of MWCNT-CPEs in $0.1 \mathrm{M} \mathrm{H}_{2} \mathrm{SO}_{4}$ at and the $\mathrm{CV}$ of $5 \times 10^{-4} \mathrm{M}$ simvastatin (SIM) in $0.1 \mathrm{M} \mathrm{H}_{2} \mathrm{SO}_{4}$ with MWCNTs, at a potential scan rate of $50 \mathrm{mV} \cdot \mathrm{s}^{-1}$. The inset shows the electrochemical oxidation mechanism of SIM.

The changes in the peak potential and peak current are presented in Figure 5. As seen in Figure 5B, the peak potential shifts to less positive potentials upon increasing the $\mathrm{pH}$ from 1 to 7 . In this $\mathrm{pH}$ range, the $\mathrm{pH}$ dependency of the peak potential follows Equation $(1) .(R=0.948)$

$$
E_{p}(\mathrm{mV})=-30.693 \cdot \mathrm{pH}+1240.5
$$

However, in the $\mathrm{pH}$ range of 7 to 9 , the peak potential increases with the $\mathrm{pH}$. The slope of the $\mathrm{pH}$ dependency of the peak potential ( $\mathrm{pH}=1$ to 7 ) is close to the theoretical value corresponding to the mechanism in which two protons and an electron are involved. However, the redox mechanism reported for the oxidation of SIM is a reaction involving two electrons and two protons. The abnormal variation of the peak potential with $\mathrm{pH}$, which was also previously observed [21,23], might arise from the coexistence of SIM and its hydrolyzed product, since SIM might be hydrolyzed into simvastatin acid ( $\beta, \delta$-dihydroxyl acid). [23,33].

The dependence of the oxidation peak current on the potential scan rate was also studied. The results are shown in Figure 6A,B. The oxidation peak shifts to a more positive potential upon increasing the scan rate, which confirms the irreversibility of the oxidation of SIM. The dependence of the peak current on the potential scan rate in logarithmic coordinates is shown in Figure $6 \mathrm{C}$. The dependency follows Equation $(2)(R=0.988)$.

$$
\log I(\mu \mathrm{A})=0.8007 \cdot \log v\left(\mathrm{mVs}^{-1}\right)-0.7908 .
$$

Furthermore, the dependency of the peak current on the square root of the scan rate (Figure 6D) is described by Equation $(3)(R=0.977)$.

$$
I(\mu \mathrm{A})=1.0837 \cdot v^{0.5}\left(\mathrm{mVs}^{-1}\right)-3.0866
$$

Since the slope of Equation (2) is between the theoretical values of 0.5 and 1.0, which are the theoretical values of the diffusion- and adsorption-controlled mechanisms, respectively [34], it can be concluded that a combination of the two mechanisms is responsible for the mass transport to 
the electrode. However, since the slope is close to 1.0, the dominant mechanism is adsorption. Furthermore, the poor linearity of Equation (3) confirms that diffusion is not the main mechanism of the mass transport.

The mechanism of the oxidation of SIM on the developed electrode was also investigated by performing 10 repetitive CVs of SIM in $0.1 \mathrm{M} \mathrm{H}_{2} \mathrm{SO}_{4}$ (Figure S2). The first cycle shows an oxidation peak at $1.10 \mathrm{~V}$. Upon increasing the number of cycles, the peak current decreases and the peak potential shifts to more positive potentials. The shift of the oxidation peak to more positive potentials is due to the adsorption of SIM onto the electrode surface, which changes the physicochemical properties of the electrode surface, including its conductivity and catalytic capability.

The developed electrode was used to drive the Tafel plot in a $5 \times 10^{-4} \mathrm{M}$ solution of SIM at a potential scan rate of $50 \mathrm{mV} \cdot \mathrm{s}^{-1}$. The Tafel equation (Equation (4)) [35] was used to determine the transfer coefficient and the exchange current.

$$
\log I=\log I_{0} \frac{(1-\alpha) n F}{2.30 R T} \eta,
$$

where $I_{0}$ is the exchange current, $I$ is the current, $\eta$ is the overvoltage, and $n$ is the number of transferred electrons. The transfer coefficient $\alpha$ was calculated to be 0.07 for this two-electron transfer process. The exchange current was also estimated from the intercept to be $1.8 \times 10^{-9} \mathrm{~A}$.
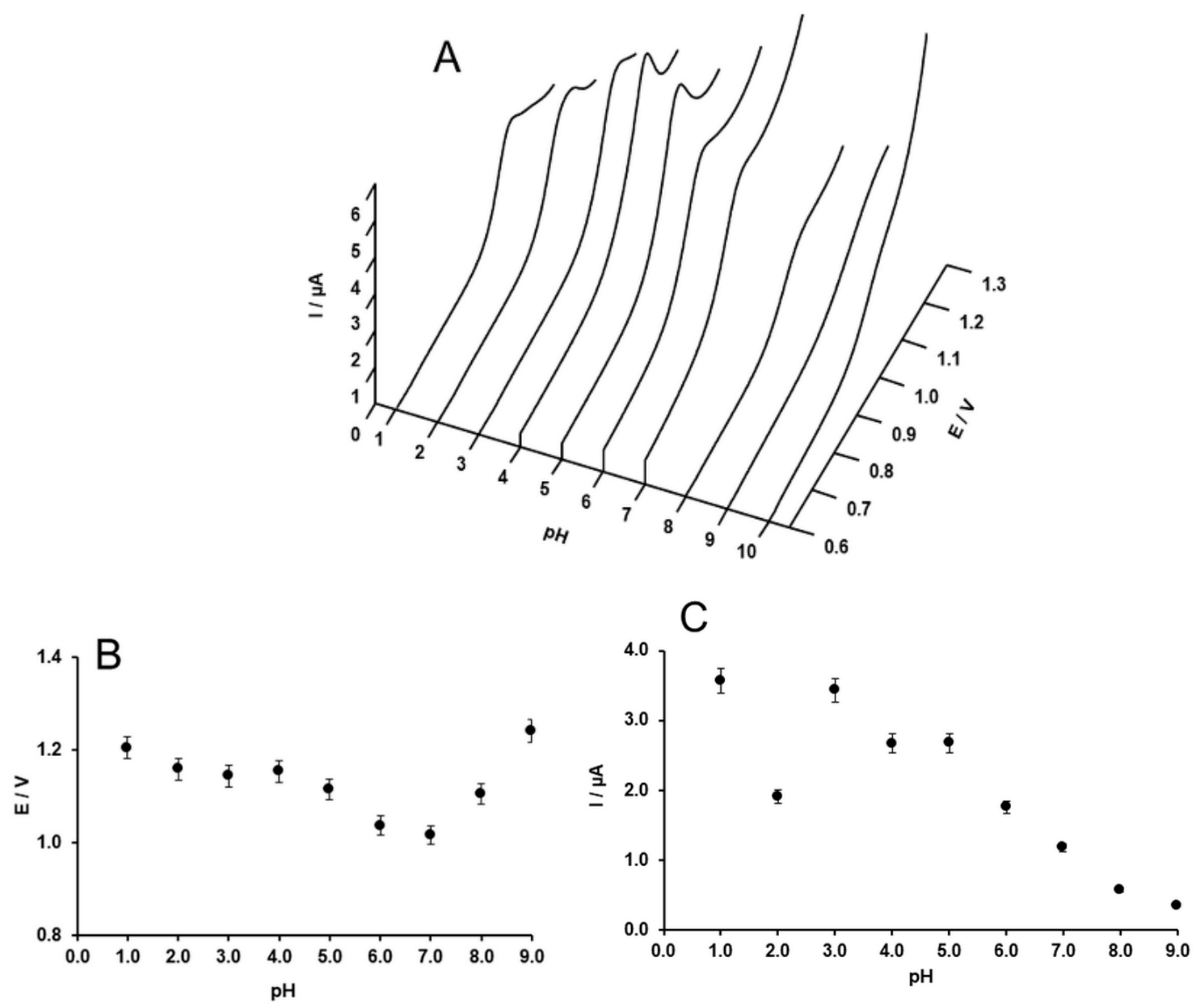

Figure 5. (A) Forward scan of CVs of $5 \times 10^{-4} \mathrm{M} \mathrm{SIM}$ in $0.1 \mathrm{M} \mathrm{H}_{2} \mathrm{SO}_{4}$ at various $\mathrm{pH}$ values, with a potential scan rate $50 \mathrm{mV} \cdot \mathrm{s}^{-1}$; (B) $\mathrm{pH}$ dependence of the peak potential; (C) $\mathrm{pH}$ dependence of the peak current. 

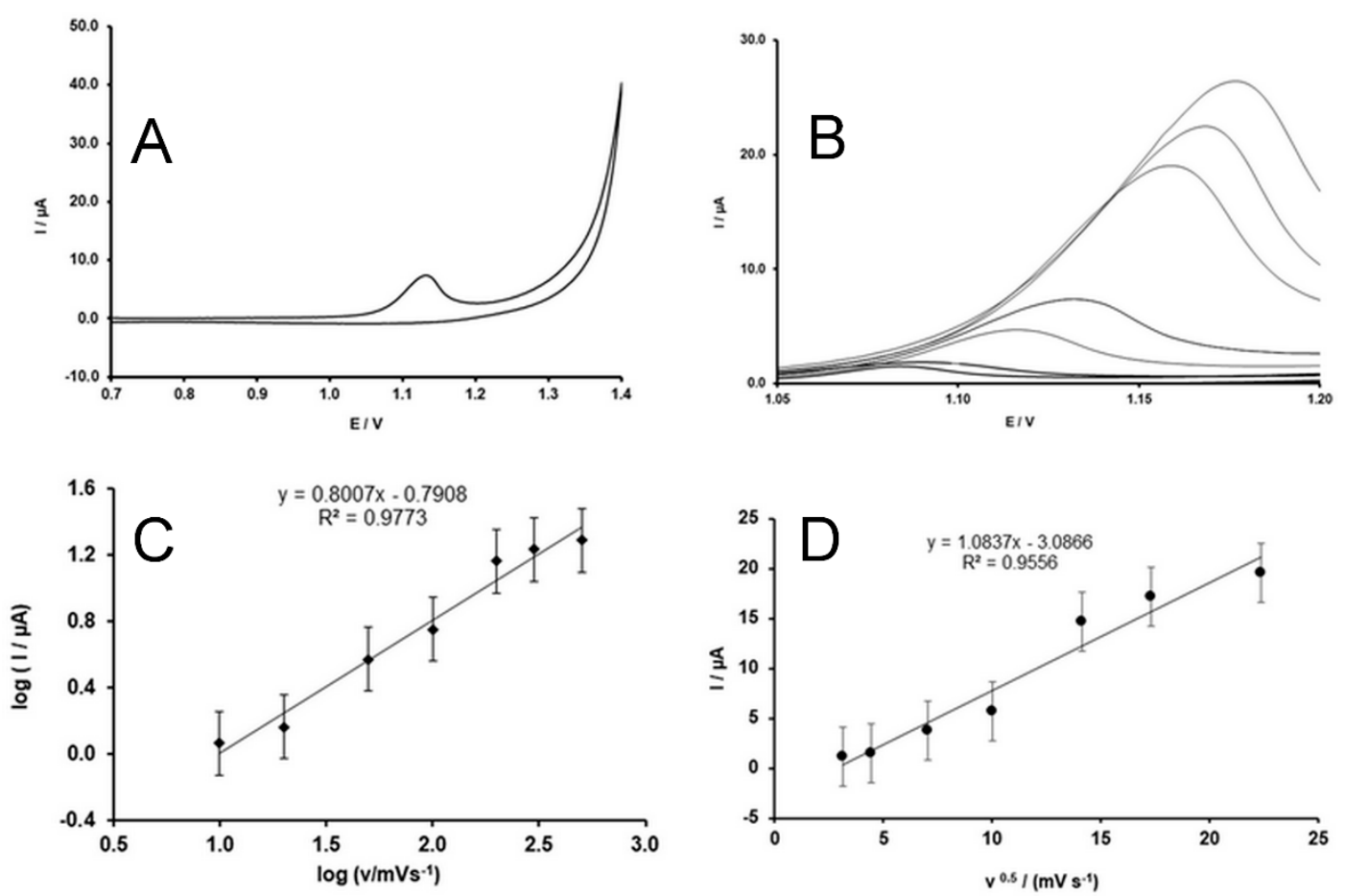

Figure 6. (A) $\mathrm{CV}$ of $5 \times 10^{-4} \mathrm{M}$ SIM in $0.1 \mathrm{M} \mathrm{H}_{2} \mathrm{SO}_{4}$ at $100 \mathrm{mV} \cdot \mathrm{s}^{-1}$; (B) the forward scan of CVs at various potential scan rates $\left(10,20,50,100,200,300\right.$, and $500 \mathrm{mV} \cdot \mathrm{s}^{-1}$ ) (only a potential range related to the peak is shown to see the peaks well); (C) scan rate dependence of the oxidation peak current in logarithmic coordinates; (D) dependence of the oxidation peak current on the square root of the scan rate.

\subsection{Analytical Parameters and Validation of the Method}

Figure 7 shows the differential pulse voltammogram (DPV) of SIM on three kinds of electrodes. As seen, the SIM oxidation peak possesses the lowest baseline current in the case of CPE. Compared to $\mathrm{CPE}$ and GC, the developed electrode shows a higher current attitude response, which is due to the synergetic effect of the MWCNTs incorporated in the carbon paste. Probably due to the higher hydrophobicity of the carbon paste, the adsorption of the SIM onto its surface takes place, while the presence of the MWCNTs increases the conductivity of the electrode and increases the peak current attitude.

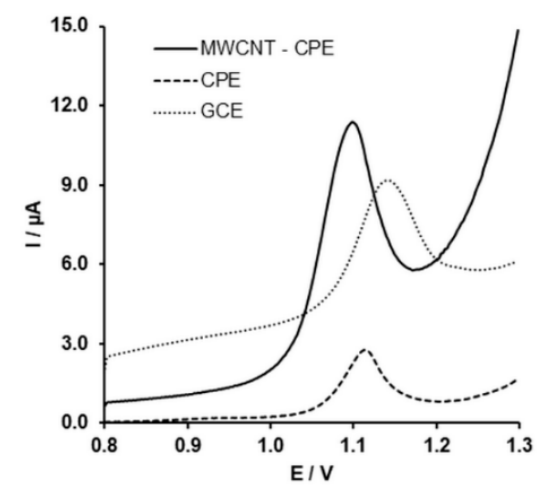

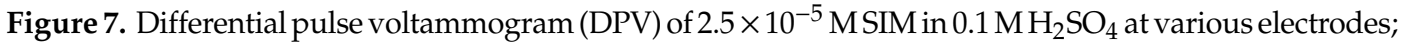
step potential: $5 \mathrm{mV}$; modulation amplitude: $100 \mathrm{mV}$; modulation time: $0.04 \mathrm{~s}$; interval time: $0.1 \mathrm{~s}$.

Moreover, the oxidation peak shifts to the less positive potential at the developed electrode due to the catalytic effect of the MWCNTs. Thus, the developed electrode was used to study the concentration 
dependence of the peak current. As seen in Figure 8A, the peak current increases linearly with the concentration of the SIM in solution. The concentration dependence of the peak current (Figure 8B) is defined by Equation (5) $(R=0.998)$.

$$
I(\mu \mathrm{A})=0.1206 \cdot \mathrm{C}(\mu \mathrm{M})-0.0531
$$
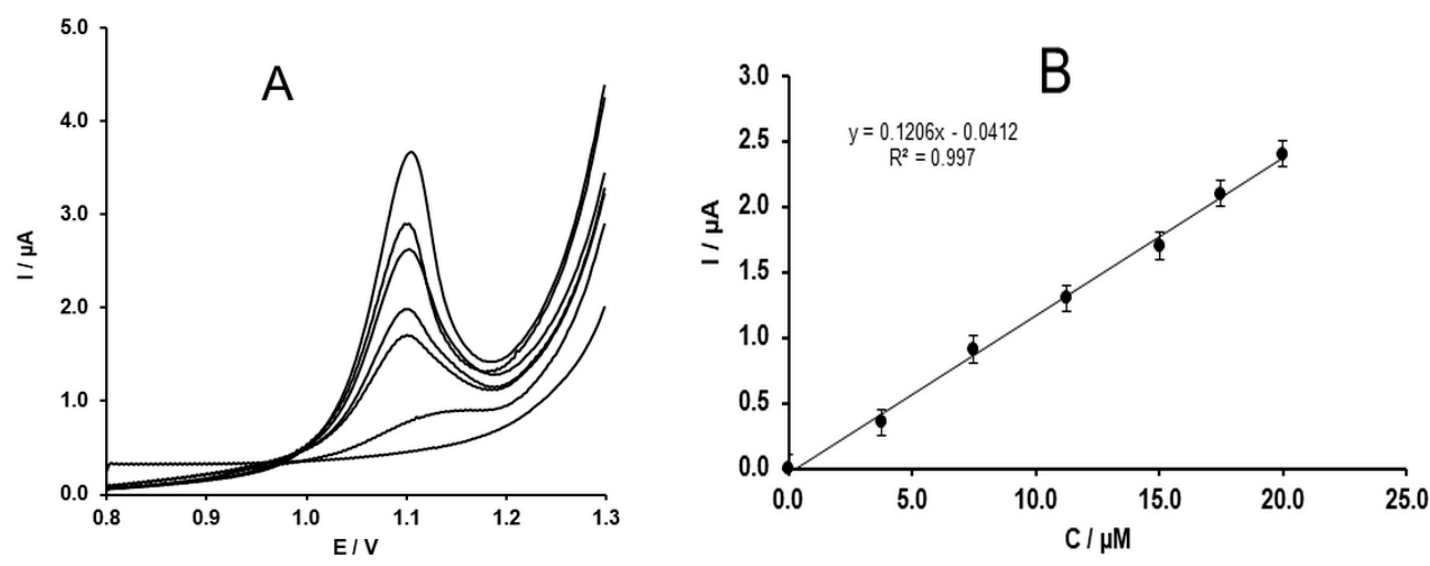

Figure 8. (A) DPV of SIM recorded at different concentrations $(0,3.75,7.5,11.25,15,17.5$, and $20 \mu \mathrm{M})$;

(B) concentration dependence of the SIM oxidation peak current.

\subsection{Determination of SIM in Pharmaceutical Dosage Form and Its Assay in Spiked Plasma}

The possibility of the application of the developed method for the direct determination of SIM content in a commercial tablet was investigated using the standard addition method without any filtration or other pre-treatments. The results are shown in Figure 9 and Table 1. Based on the obtained results, the determination of SIM in drug dosage form can be carried out with the developed method with good accuracy (relative recovery rate $=99.7 \%$ ) and reproducibility (relative standard deviation $(\mathrm{RSD} \%)=1.8)$. The determination of SIM in human plasma, which is a more complicated matrix, was also performed. The plasma was spiked with a known concentration of SIM and then the spiking recovery rate was determined using the standard addition method. The results are presented in Table 1. The satisfactory nature of the SIM analysis in plasma can be confirmed from the high reproducibility $(\mathrm{RSD} \%=2.3)$ and high accuracy of the measurement (spiking recovery rate $=99.5 \%)$ (Table 1$)$. It must be mentioned that the concentration of the SIM in plasma is very low (1-15 nM). However, the developed method can be used for the determination of SIM concentration in plasma at levels attributed to the pleiotropic effects $(1-50 \mu \mathrm{M})[8-11]$.
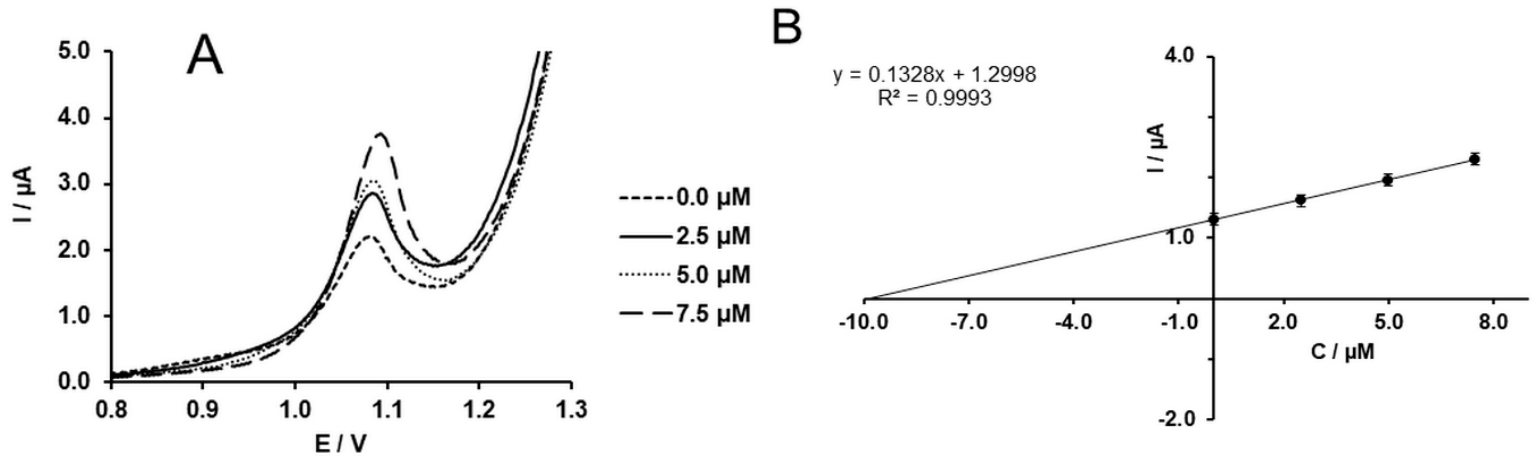

Figure 9. (A) DPVs of solution of $7.5 \mu \mathrm{M}$ SIM prepared in tablet form and three standard additions of $5 \mu \mathrm{M}, 7.5 \mu \mathrm{M}$, and $10 \mu \mathrm{M}$; (B) standard addition curve in which the extrapolations show the initial concentration of SIM in the measuring solution. 
Table 1. The analytical parameters obtained for the calibration of standards, drug dosage form and plasma sample.

\begin{tabular}{|c|c|c|c|c|c|}
\hline $\begin{array}{l}\text { Calibration with } \\
\text { Standards }\end{array}$ & & Drug Dosage Form & & Spiked Plasma & \\
\hline Peak potential $(\mathrm{V})$ & 1.10 & Potential & 1.10 & Potential & 1.10 \\
\hline Linearity range $(\mu \mathrm{M})$ & $3.75-20$ & Slope & 0.1183 & Slope & 0.154 \\
\hline Slope $\left(\mu \mathrm{A} \cdot \mu \mathrm{M}^{-1}\right)$ & $0.121 \pm 0.005$ & Intercept & 0.8854 & Intercept & 1.532 \\
\hline Intercept & 0.041 & Correlation coefficient $r$ & 0.996 & Correlation coefficient $r$ & 0.999 \\
\hline Correlation coefficient $(r)$ & $0.998 \pm 0.004$ & Labelled claim (mg) & 10 & Spiked $(\mu \mathrm{M})$ & 10 \\
\hline $\operatorname{LOD}^{1}(\mu \mathrm{M})$ & $2.4 \times 10^{-7}$ & Found (mg) & 9.97 & Found $(\mu \mathrm{M})$ & 9.95 \\
\hline LOQ $(\mu \mathrm{M})$ & $8.0 \times 10^{-7}$ & Recovery rate \% & 99.7 & Bias \% & 0.5 \\
\hline $\mathrm{RSD} \%(n=8)$ & 4.8 & Bias \% & 0.3 & Spiking Recovery rate $\%$ & 99.5 \\
\hline Confidence interval ${ }^{2}$ & $\pm 1.0 \times 10^{-8}$ & $\mathrm{RSD} \%(n=3)$ & 1.8 & $\operatorname{RSD} \%(n=3)$ & 2.3 \\
\hline
\end{tabular}

\subsection{Interference Study}

The oxidation peak of $5 \times 10^{-6} \mathrm{M}$ SIM was recorded in the presence of potential interferents such as ascorbic acid and citric acid in 100-fold higher concentration. It was found that the peak current and potential were not affected due to the presence of these chemicals (Figure S3).

\section{Materials and Methods}

\subsection{Chemicals}

Simvastatin was kindly provided by Prof. Sibel Ozcan (Faculty of Pharmacy, Ankara University, Department of Analytical Chemistry), and its pharmaceutical dosage form (Simgal) was provided by TEVA Czech. Ind. (Opava, Czech Republic). All chemicals for the preparation of buffers and supporting electrolytes were reagent-grade (Sigma-Aldrich, St. Louis, MO, USA). A stock solution of SIM $\left(10^{-2} \mathrm{M}\right)$ was prepared in ethanol, and the required concentration of SIM was prepared by dilution. The final percentage of ethanol was kept at 10\% in all solutions. Solid MWCNTs (purified to more than $95 \%$ carbon with an average diameter of $10 \mathrm{~nm}$ and an average length of $1.5 \mu \mathrm{m}$ ) were purchased from Sigma. Expanded graphite for preparation of the CPE was purchased from Graphite Tyn Ltd. (Tyn nad Vltavou, Czech Republic). The paraffin oil was also purchased from Sigma. Ferrocene methanol $(\mathrm{FcOH})$, which was used as the mediator for the SECM imaging, was purchased from ABCR GmbH chemicals (Karlsruhe, Germany).

\subsection{Apparatus}

Voltammetric measurements were carried out using a potentiostate/galvanostate AUTOLAB PGSTAT 302 controlled by Nova software (EcoChemie, Utrecht, the Netherlands). The conventional three-electrode configuration for the electrochemical experiments was used. The constructed CPEs and MWCNT-CPEs were used as the working electrodes, while an $\mathrm{Ag} / \mathrm{AgCl}(3 \mathrm{M} \mathrm{KCl})$ electrode and a platinum wire served as the reference and auxiliary electrodes, respectively. The measurements were carried out in one-compartment voltammetric cells (10-20 mL) at conditioned room temperature $(23 \pm 1 \mathrm{C}$ ). The $\mathrm{pH}$ measurements were performed using a pH meter Model Sentix 81 (WTW, Weilheim, Germany) with a combined electrode (glass electrode $=\mathrm{Ag} / \mathrm{AgCl}(3 \mathrm{M} \mathrm{KCl})$ reference electrode) with an accuracy of $\mathrm{pH} \pm 0.05$.

A CHI 900 set-up (CH Instrument Inc., Bee Cave, TX, USA) was used for the scanning electrochemical microscopy (SECM) measurements. A Pt ultra-microelectrode $(\mathrm{d}=10 \mu \mathrm{m})$ served as the SECM tip (RG factor $=10)$, while MWCNT-CPEs prepared with different MWCNT mass ratios were used as SECM substrates. The counter electrode was a platinum wire, and the reference electrode was an $\mathrm{Ag} / \mathrm{AgCl}$ $(3 \mathrm{M} \mathrm{KCl})$ electrode. $\mathrm{FCOH} 1 \mathrm{mM}$ in $0.1 \mathrm{M} \mathrm{KCl}$ was used as a redox mediator. All potentials are referred to the reference electrode. The scanning electron microscope MIRA2 LMU (Tescan, a.s., Brno, 
Czech Republic) was also used for imaging the prepared MWCN-CPE electrodes. An accelerating voltage of $15 \mathrm{kV}$ was applied to produce an electron beam of about $1 \mathrm{nA}$ to visualize the electrode surface at a working distance of $4 \mathrm{~mm}$. Atomic force microscopy (AFM) for the electrode surface characterization was carried out with a dimension FastScan Bio from Bruker (Billerica, MA, USA) operating with Gwydion 2.52 for data visualization [36].

\subsection{Preparation of the Working Electrode}

The MWCNT-modified carbon paste electrodes (MWCNT-CPEs) were prepared by intimately hand-mixing graphite powder and MWCNTs with highly viscous paraffin oil in three different ratios (a: 55\%/15\%/30\%, b: 45\%/25\%/30\%, and c: 35\%/35\%/30\% graphite powder, MWCNTs, and paraffin oil, respectively). All the components were homogenized to obtain a mixture that was subsequently packed into a piston-driven carbon paste holder (with an internal diameter of $2 \mathrm{~mm}$ ). Whenever needed, the surface of the MWCNT-CPEs was mechanically renewed by extruding ca. $0.5 \mathrm{~mm}$ of the paste out of the electrode holder and smoothing with a wet filter paper. To find the optimum combination, various mass percentages of MWCNTs in the paste were utilized and examined.

\subsection{Pharmaceutical Dosage Form Assay Procedure}

Ten tablets of Simgal (each tablet contains $10 \mathrm{mg}$ of SIM) were weighed and finely powdered. An amount of pharmaceutical powder equivalent to $10^{-2}$ M SIM (10 mL) was dissolved in ethanol. The complete dissolution was ensured by $10 \mathrm{~min}$ of sonication. The desired concentration of SIM solution was then prepared by taking the aliquots of the clear supernatant liquor and diluting with the supporting electrolyte. For pharmaceutical dosage form analysis, the standard addition method was carried out, in which a known concentration of SIM solution prepared using the tablet was subjected to three additions of small volumes of stock solution of SIM.

\subsection{Recovery Studies in Spiked Human Plasma Samples}

The human plasma samples, which were obtained from healthy individuals, were stored frozen until the assay. To prepare $2 \mathrm{~mL}$ of $10^{-3} \mathrm{M}$ SIM in plasma, after gentle melting at room temperature, the aliquots of plasma were spiked with the required amount of SIM stock solution and treated with $700 \mu \mathrm{L}$ of acetonitrile as a plasma protein precipitating agent; then, the same plasma sample was added to reach $2 \mathrm{~mL}$. After that, the sample was subjected to $5 \mathrm{~min}$ of agitation and then $10 \mathrm{~min}$ of centrifugation at $16,500 \mathrm{RCF}$ in order to precipitate the protein residues. The desired concentrations of the plasma samples were prepared by taking the supernatants and mixing them with the required amount of the supporting electrolyte. It must be mentioned that the ethanol percentages in all the analyzed samples were the same.

\subsection{Procedure}

DPV was used for electroanalytical determination of SIM with the following parameters: step potential: $5 \mathrm{mV}$; modulation amplitude: $100 \mathrm{mV}$; modulation time: $0.04 \mathrm{~s}$; interval time: $0.1 \mathrm{~s}$.

To record the approach curve, a potential of $600 \mathrm{mV}$ was applied to the tip where the oxidation of $\mathrm{FcOH}$ to $\mathrm{FcOH}_{\mathrm{ox}}$ takes place. At the conductive surface, the generated $\mathrm{FCOH}_{\mathrm{ox}}$ is reduced to the parent $\mathrm{FCOH}$, which is transferred to the tip and increases the tip current. On the contrary, where the substrate surface insulates the process, the diffusion of the $\mathrm{FcOH}$ from the bulk solution to the tip is limited, which decreases the tip current.

The probe was then approached to the substrate at a tip scan rate of $0.5 \mu \mathrm{m} \cdot \mathrm{s}^{-1}$. When the tip is far from the substrate and the potential is applied, $\mathrm{FCOH}_{\mathrm{ox}}$ is generated and the steady-state current $i_{T, \infty}$ is obtained, which is controlled by the rate of mass transfer by diffusion of FcOH from the bulk solution to the electrode surface.

The current $i_{T}$ increases upon approaching the tip to the substrate because of positive feedback. The approach was interrupted when $i_{T}=1.25 i_{T, \infty}$. At this magnitude of current, a distance of $10 \mu \mathrm{m}$ 
between the tip and the substrate is expected based on the theoretical curve of distance (d) dependency of $i_{T}$ for the utilized ultra-microelectrode (UME) [37]. The constant height mode was used to record the images at a tip scan rate of $1 \mu \mathrm{m} \cdot \mathrm{s}^{-1}$ and an area of $100 \mu \mathrm{m} \times 100 \mu \mathrm{m}$ of the samples.

\section{Conclusions}

The bulk-modified MWCNT-CPEs were prepared and characterized to find the optimum amount of MWCNTs in the paste. The characterization was performed using SECM, SEM, and AFM. Based on the obtained results, the $25 \%$ MWCNT-CPE was the optimum electrode in terms of the homogeneity of the prepared paste. Then, the 25\% MWCNT-CPE was used for the analysis of SIM in pharmaceutical dosage form, as well as in spiked human plasma. The results confirmed the satisfactory nature of the developed method considering the calculated parameters including bias, relative standard deviation (RSD\%), and the recovery rate, as reported in Table 1 . The low limit of detection and limit of quantification, in addition to the slope of the calibration curve, proved the sensitivity of the prepared electrode. The advantages of the developed method compared to other electroanalytical methods include simple preparation of the electrode and renewal of the electrode surface, whereas any toxic compounds such as mercury or other heavy metals were not used, and its sensitivity is higher compared to the bare GC and CPE. The developed method offers a simple screening approach for preliminary monitoring. Furthermore, the developed method can be used for rapid but accurate determination of SIM in pharmaceutical dosage form and in plasma samples when its concentration corresponds to the pleiotropic effects.

Supplementary Materials: The following are available online: Figures S1-S3.

Author Contributions: A.M.A. conceived and designed the experiments, analyzed the data, and wrote the paper; L.R. was the lab manager and supervised the writing of the manuscript.

Funding: This research was funded by the Czech Ministry of Education in the framework of the National Sustainability Program, grant number LO1401 INWITE. For the research, the infrastructure of the SIX Center was used.

Acknowledgments: We thank Tereza Sojková for her technical assistance. We also acknowledge Sibel Ozcan for kindly providing the SIM and MU L. S. for providing Simgal. Furthermore, Jan Pribyl is acknowledged because of providing AFM images.

Conflicts of Interest: The authors declare no conflict of interest.

\section{References}

1. Pedersen, T.R.; Tobert, J.A. Simvastatin: A review. Expert Opin. Pharmacother. 2004, 5, 2583-2596. [CrossRef] [PubMed]

2. Zhao, J.J.; Xie, I.H.; Yang, A.Y.; Roadcap, B.A.; Rogers, J. Quantitation of simvastatin and its $\beta$-hydroxy acid in human plasma by liquid-liquid cartridge extraction and liquid chromatography/tandem mass spectrometry. J. Mass Spectrom. 2000, 35, 1133-1143. [CrossRef]

3. Liao, J.K. Effects of statins on 3-hydroxy-3-methylglutaryl coenzyme a reductase inhibition beyond low-density lipoprotein cholesterol. Am. J. Cardiol. 2005, 96, 24-33. [CrossRef] [PubMed]

4. Willey, J.Z.; Elkind, M.S. 3-Hydroxy-3-methylglutaryl-Coenzyme A Reductase Inhibitors in the Treatment of Central Nervous System Diseases. Arch. Neurol. 2010, 67, 1062-1067. [CrossRef] [PubMed]

5. Subhan, M.; Faryal, R.; Macreadie, I. Exploitation of Aspergillus terreus for the Production of Natural Statins. J. Fungi 2016, 2, 13. [CrossRef] [PubMed]

6. Bonetti, P.; Lerman, L.; Napoli, C.; Lerman, A. Statin effects beyond lipid lowering-Are they clinically relevant? Eur. Heart J. 2003, 24, 225-248. [CrossRef]

7. Ramkumar, S.; Raghunath, A.; Raghunath, S. Statin therapy: Review of safety and potential side effects. Acta Cardiol. Sin. 2016, 32, 631.

8. Björkhem-Bergman, L.; Lindh, J.D.; Bergman, P. What is a relevant statin concentration in cell experiments claiming pleiotropic effects? Brit. J. Clin. Pharmacol. 2011, 72, 164-165. [CrossRef] 
9. Bu, D.; Tarrio, M.; Grabie, N.; Zhang, Y.; Yamazaki, H.; Stavrakis, G.; Maganto-Garcia, E.; Pepper-Cunningham, Z.; Jarolim, P.; Aikawa, M. Statin-induced Kruppel-like factor 2 expression in human and mouse T cells reduces inflammatory and pathogenic responses. J. Clin. Investig. 2010, 120, 1961-1970. [CrossRef]

10. Chow, O.A.; von Köckritz-Blickwede, M.; Bright, A.T.; Hensler, M.E.; Zinkernagel, A.S.; Cogen, A.L.; Gallo, R.L.; Monestier, M.; Wang, Y.; Glass, C.K. Statins enhance formation of phagocyte extracellular traps. Cell Host Microbe 2010, 8, 445-454. [CrossRef]

11. Youssef, S.; Stüve, O.; Patarroyo, J.C.; Ruiz, P.J.; Radosevich, J.L.; Hur, E.M.; Bravo, M.; Mitchell, D.J.; Sobel, R.A.; Steinman, L. The HMG-CoA reductase inhibitor, atorvastatin, promotes a Th2 bias and reverses paralysis in central nervous system autoimmune disease. Nature 2002, 420, 78. [CrossRef] [PubMed]

12. Carlucci, G.; Mazzeo, P.; Biordi, L.; Bologna, M. Simultaneous determination of simvastatin and its hydroxy acid form in human plasma by high-performance liquid chromatography with UV detection. J. Pharmaceut. Biomed. 1992, 10, 693-697. [CrossRef]

13. Jemal, M.; Ouyang, Z.; Powell, M.L. Direct-injection LC-MS-MS method for high-throughput simultaneous quantitation of simvastatin and simvastatin acid in human plasma. J. Pharmaceut. Biomed. 2000, 23, 323-340. [CrossRef]

14. Ochiai, H.; Uchiyama, N.; Imagaki, K.; Hata, S.; Kamei, T. Determination of simvastatin and its active metabolite in human plasma by column-switching high-performance liquid chromatography with fluorescence detection after derivatization with 1-bromoacetylpyrene. J. Chromatogr. B 1997, 694, 211-217. [CrossRef]

15. Yang, H.; Feng, Y.; Luan, Y. Determination of Simvastatin in human plasma by liquid chromatography-mass spectrometry. J. Chromatogr. B 2003, 785, 369-375. [CrossRef]

16. Takano, T.; Abe, S.; Hata, S. A selected ion monitoring method for quantifying simvastatin and its acid form in human plasma, using the ferroceneboronate derivative. Biol. Mass Spectr. 1990, 19, 577-581. [CrossRef]

17. Srinivasu, M.; Raju, A.N.; Reddy, G.O. Determination of lovastatin and simvastatin in pharmaceutical dosage forms by MEKC. J. Pharmaceut. Biomed. 2002, 29, 715-721. [CrossRef]

18. El-Din, M.M.S.; Attia, K.A.; Nassar, M.W.; Kaddah, M.M. Colorimetric determination of simvastatin and lovastatin in pure form and in pharmaceutical formulations. Spectrochim. Acta A 2010, 76, 423-428. [CrossRef]

19. Al-Ghamdi, A.F.; Hefnawy, M.M.; El-Shabrawy, Y. Non-extractive ultra-trace determination of simvastatin in biological fluids by voltammetric method via complexation with cadmium. Dig. J. Nanomater. Biostruct. 2014, 9, 355-368.

20. Nigović, B.; Komorsky-Lovrić, Š.; Devčić, D. Rapid voltammetric identification and determination of simvastatin at trace levels in pharmaceuticals and biological fluid. Croatica Chem. Acta 2008, 81, 453-459.

21. Coruh, Ö.; Özkan, S. Determination of the antihyperlipidemic simvastatin by various voltammetric techniques in tablets and serum samples. Int. J. Pharmaceut. Sci. 2006, 61, 285-290.

22. Deepa, M.; Mamatha, G.; Naik, Y.A.; Sherigara, B.; Manjappa, S.; Vijaya, B. Electrochemical studies of simvastatin at glassy carbon electrode and immobilized by sodium dodecyl sulfate surfactant. J. Chem. Pharm. Res 2012, 4, 2803-2816.

23. Zhang, H.; Hu, C.; Wu, S.; Hu, S. Enhanced Oxidation of Simvastatin at a Multi-Walled Carbon Nanotubes-Dihexadecyl Hydrogen Phosphate Composite Modified Glassy Carbon Electrode and the Application in Determining Simvastatin in Pharmaceutical Dosage Forms. Electroanalysis 2005, 17, 749-754. [CrossRef]

24. Svancara, I.; Kalcher, K.; Walcarius, A.; Vytras, K. Electroanalysis with Carbon Paste Electrodes; CRC Press: Boca Raton, FL, USA, 2012.

25. Akhoundian, M.; Alizadeh, T.; Ganjali, M.R.; Norouzi, P. Ultra-trace detection of methamphetamine in biological samples using FFT-square wave voltammetry and nano-sized imprinted polymer/MWCNTs -modified electrode. Talanta 2019, 200, 115-123. [CrossRef]

26. Rajaei, M.; Foroughi, M.M.; Jahani, S.; Shahidi Zandi, M.; Hassani Nadiki, H. Sensitive detection of morphine in the presence of dopamine with La3+ doped fern-like $\mathrm{CuO}$ nanoleaves/MWCNTs modified carbon paste electrode. J. Mol. Liq. 2019, 284, 462-472. [CrossRef]

27. Teixeira, M.d.C.; Felix, F.S.; Thomasi, S.S.; Magriotis, Z.M.; da Silva, J.M.; Okumura, L.L.; Saczk, A.A. Voltammetric determination of organic nitrogen compounds in environmental samples using carbon paste electrode modified with activated carbon. Microchem. J. 2019, 148, 66-72. [CrossRef] 
28. Khrizanforov, M.N.; Arkhipova, D.M.; Shekurov, R.P.; Gerasimova, T.P.; Ermolaev, V.V.; Islamov, D.R.; Miluykov, V.A.; Kataeva, O.N.; Khrizanforova, V.V.; Sinyashin, O.G.; et al. Novel paste electrodes based on phosphonium salt room temperature ionic liquids for studying the redox properties of insoluble compounds. J. Solid State Electrochem. 2015, 19, 2883-2890. [CrossRef]

29. Musameh, M.; Wang, J.; Merkoci, A.; Lin, Y. Low-potential stable NADH detection at carbon-nanotube-modified glassy carbon electrodes. Electrochem. Commun. 2002, 4, 743-746. [CrossRef]

30. Fanjul-Bolado, P.; Queipo, P.; Lamas-Ardisana, P.J.; Costa-García, A. Manufacture and evaluation of carbon nanotube modified screen-printed electrodes as electrochemical tools. Talanta 2007, 74, 427-433. [CrossRef]

31. Ashrafi, A.M.; Kurbanoglu, S.; Vytřas, K.; Uslu, B.; Ozkan, S.A. Electrochemical mechanism and sensitive assay of antiretroviral drug Abacavir in biological sample using multiwalled carbon nanotube modified pyrolytic graphite electrode. J. Electroanal. Chem. 2014, 712, 178-184. [CrossRef]

32. Mikysek, T.; Švancara, I.; Kalcher, K.; Bartoš, M.; Vytřas, K.; Ludvík, J. New approaches to the characterization of carbon paste electrodes using the ohmic resistance effect and qualitative carbon paste indexes. Anal. Chem. 2009, 81, 6327-6333. [CrossRef] [PubMed]

33. Friedrich, J.; Žužek, M.; Benčina, M.; Cimerman, A.; Štrancar, A.; Radež, I. High-performance liquid chromatographic analysis of mevinolin as mevinolinic acid in fermentation broths. J. Chromatogr. A 1995, 704, 363-367. [CrossRef]

34. Bard, A.J.; Faulkner, L.R.; Leddy, J.; Zoski, C.G. Electrochemical Methods: Fundamentals and Applications; Wiley: New York, NY, USA, 1980; Volume 2, pp. 26-52.

35. Tafel, J. Über die Polarisation bei kathodischer Wasserstoffentwicklung. Zeitschrift für Physikalische Chemie 1905, 50, 641-712. [CrossRef]

36. Nečas, D.; Klapetek, P.J.O.P. Gwyddion: An open-source software for SPM data analysis. Open Phys. 2012, 10, 181-188. [CrossRef]

37. Bard, A.J.; Mirkin, M.V. Scanning Electrochemical Microscopy; CRC Press: Boca Raton, FL, USA, 2012.

Sample Availability: Not available.

(C) 2019 by the authors. Licensee MDPI, Basel, Switzerland. This article is an open access article distributed under the terms and conditions of the Creative Commons Attribution (CC BY) license (http://creativecommons.org/licenses/by/4.0/). 